\title{
COMPARISON OF HIGH RELIABILITY ORGANIZATIONS (HROS)
}

\author{
Paula Lewis, Federal Aviation Administration, Washington, DC
}

\section{Abstract}

High Reliability Organizations (HROs) are defined as enterprises that perform missions involving processes that require extraordinary measures to maintain low risk in the presence of disruptions that could result in catastrophic events (e.g. radiation or well leaks leading to long-term environmental damage) or fatalities (e.g. epidemics, air traffic control). These types of enterprises occur in multiple domains ranging from health care, processing of raw materials, energy and water distribution, and vehicle systems management and control.

The existing literature describes the diverse characteristics of HROs and the organizational design to manage these characteristics. This paper describes a comparison of the properties of the enterprises ("what") and the organizational structures ("how") used to achieve the desired high reliability for: (1) Federal Aviation Administration's (FAA) Air Traffic Control System, (2) Pacific Electric and Gas Company's Diablo Canyon Nuclear Power Plant (DCNPP), and (3) Cincinnati Children's Hospital Medical Center (CCHMC).

A detailed review of HRO literature, case studies and organizational reports, performance plans and technical plans identify the following properties of the HRO design: (1) all three domains require the employment of skilled personnel that are certified by a regulatory (federal or state) authority and require specialized training; (2) certification of operations is overseen by regulatory authorities (federal and state); and (3) metrics are focused on risks. Examples of the metrics for each enterprise are as follows: runway incursions, system risk event rates, number of near midair collisions for air traffic control; length and quality of life, pain levels, infections for children's health care; and nuclear power plants use reactor accidents, acute radiation exposures resulting in fatalities, release of radioactive materials that result in significant radiation exposure for nuclear power plants. These enterprises focus on making consistently good decisions that result in higher quality, safer and more reliable operations.

\section{Introduction}

Highly Reliability Organizations operate in the midst of complex and dynamic environments that include fluctuating energy prices, limited natural resources, and global, political and economic uncertainty. They experience ongoing external and internal pressure to deliver safe services, increase efficiency and productivity, as well as, being good stewards of the environment.

Diverse as HROs may seem, they are grouped together because they all operate in an unforgiving social and political environment. The operating systems are rich with the potential for mistakes. (Rochlin, 1993) Hospitals, for example, have the potential for an increase in errors as a result of complex procedures, technology and the need for multiple teams that must collaborate to deliver patient care.

The primary concern for HROs is reliability (the ability to maintain performance during complex, uncertain, and unexpected situations). (Weick, et al., 1999, Roberts, 1990) HROs have the capacity to: (1) identify early warning signs and execute responses to maintain or restore the operation of the system; (2) predict and avoid possible future errors; and (3) measure performance against safety targets. Trained personnel, systems and processes are in place to avoid potentially catastrophic errors.

For example, the total number of Near Midair Collisions (NMACs) has decreased from 108 to 57 from fiscal years January 2007 through September 2009 as shown in Table 1 [1].

Table 1. Near Midair Collisions

\begin{tabular}{|c|l|l|c|c|c|}
\hline & \multicolumn{5}{|l|}{ Months } \\
\hline FY & Jan-Mar & Apr-Jun & Jul-Sep & Oct-Dec & Total \\
\hline 07 & 30 & 24 & 33 & 21 & 108 \\
\hline 08 & 28 & 23 & 19 & 22 & 92 \\
\hline 09 & 11 & 21 & 18 & 7 & 57 \\
\hline
\end{tabular}

There is extensive detail in the existing literature on the diverse attributes of HROs: (Perrow, 1984; Weick et.al. 1999; Klien et. al. 1995; Pronovost, et.al. 
2006; Hines et.al. 2008; Frederickson, et.al. 2002). The purpose of this paper is to compare eight HRO properties and performance measures from the organizational and policy perspective. The eight attributes include: decision making and organizational structure, personnel requirements, safety, funding, training, technical competence, and system improvement.

The comparison describes the organizational properties ("what") and organizational structure ("how") the enterprise uses to achieve desired high reliability for: Federal Aviation Administration's (FAA) Air Traffic Control System, Pacific Electric and Gas Company's Diablo Canyon Nuclear Power Plant (DCNPP), and Cincinnati Children's Hospital Medical Center (CCHMC).

The methodology includes a detailed review of the HRO literature, case studies, organizational performance plans, annual reports (including financial data), policy documents and technical plans

The main results of this review are as follows:

- The three HROs are more similar than different

- Financial structure and geographical location do not impact organizational performance

- All three have state and/or federal regulatory oversight

- Formal system improvement programs for safety are in place (e.g. multi-disciplined teams, automated reporting tools and nonpunitive voluntary safety reporting)

- In air traffic control, lines of authority shift to specialist with the most knowledge of how to defuse potentially dangerous situations and medical and nuclear power use a centralized team approach to make emergency decisions

This paper is organized as follows: The next section describes the organizational characteristics of each domain. The following section provides an overview of the HRO literature. The subsequent section describes the eight HRO attributes. The next section provides an overview of attributes by enterprise. The following section contains examples of safety measures for each domain. The final section contains the results of the HRO comparative analysis.

\section{Background}

This section describes the characteristics of each enterprise.

\section{FAA's Air Traffic Organization (ATO)}

The primary mission of air traffic control is the safe and efficient movement of aircraft in both domestic and oceanic airspace which includes $24.6 \mathrm{M}$ square miles of international oceanic airspace delegated to the FAA by the International Civil Aviation Organization (ICAO).

Air traffic operations are coordinated across the United States by over 300 air traffic control facilities (e.g. 21 Air Route Traffic Control Centers (ARTCCs), over 20 Terminal Radar Approach Control Facilities and more than 100 Towered Airports with the support of approximately 35,000 controllers, technicians, engineers and support personnel). Air traffic control is a distributed 24/7 operation with a command center flow control that ensures the safety of more than 7,000 take offs and landings per hour and 50,000 flights per day across approximately 20,000 airports within the National Airspace System [2].

Examples of stakeholders involved in aviation include labor unions, commercial and private aviation, military, airports, aviation manufactures, academia and other federal agencies (e.g. Department of Defense (DOD).

\section{The Diablo Canyon Nuclear Power Plant (DCNPP)}

The key responsibility of the Diablo Canyon Nuclear Power Plant (DCNPP) is to generate electricity through the support of approximately 1,400 highly skilled employees (e.g., engineers, chemists, nuclear physicists, radiation biologists, seismologists and security officers). The plant operates two 1,100 megawatt Westinghouse Pressurized Water Reactors (PWRs) 24/7 to generate electricity and provide power to approximately three million homes in northern and central California.

The plant is owned and managed by the Pacific Gas \& Electric (PG\&E) Company and is located on 
1,000 acres near San Luis Obispo County, California. Power is generated through a centralized operation and electricity is delivered using a decentralized distribution system. The plant's service area is 70,000 square miles in central and northern California with a population of approximately 14 million people. This is almost $10 \%$ of California's energy portfolio and $20 \%$ of the power within Pacific Gas \& Electric (PG\&E) Company's service area. The plant produces energy without greenhouse gases (GHC) (e.g., the avoidance of six to seven million tons of GHCs per year ) [3].

Included in the stakeholders are business and residential customers, investors, suppliers, federal and state regulators (e.g., Nuclear Regulatory Commission (NRC,) Department of Energy (DOE), Environmental Protection Agency (EPA), California Public Commission Utilities (CPCU) and California Energy Commission (CEC.)

\section{The Cincinnati Children's Hospital Medical Center (CCHMC)}

The primary function of the Cincinnati Children's Hospital Medical Center is to improve child health care. The hospital is a part of the Department of Pediatrics in the College of Medicine at the University of Cincinnati. The center is a not for-profit pediatric, academic, medical hospital that provides a full $24 / 7$ service. It has nine urgent care centers that operate Monday through Friday from 6:00 pm -11:00 pm, Saturday noon-7:00 pm and Sunday 11: $00 \mathrm{am}-7: 00 \mathrm{pm}$. In addition, there is one emergency room care center that operates 24/7.

The hospital provides health care for children (domestic and international) by nearly 13,000 doctors, nurses, medical staff, faculty and residents that support pediatrics, surgery, radiology and anesthesia. During the period of July 2011 - June 2012, the Center had almost 600 registered beds, logged more than 44,000 surgical hours and encountered approximately 1.1million patients including almost 124,000 emergency room visits. The emergency room care center provides medical assistance to support approximately 450,000 outpatient visits. In addition, the faculty publishes 1,400 articles in peer review journals [4].

There are several categories of medical stakeholders: patients, families, board of trustees, insurance companies, financial donors, federal and state regulators (e.g., Food \& Drug Administration (FDA), investors, and suppliers.

\section{Literature Review}

The literature summary is organized from four perspectives: engineering, organizational (including experiential, trust and communication) medical and policy.

\section{Engineering Perspectives}

Research by Perrow (1984) concludes that interactive complexity and tight coupling result in accidents that cannot be prevented. After completing the analysis of operating systems used in nuclear and chemical plants, ships, dams, aircraft and air traffic control, interactive complexity and a tightly coupled system are the two characteristics that result in an increase in system risk. Interactive complexity is the failure of two components that network in an unexpected way; while, tightly coupled systems involve processes that are part of a system that happen quickly and cannot be isolated.

The Three Mile Island (TMI) analysis reveals that the technology was tightly coupled due to timedependent processes, constant sequences and limited slack. The events that spread through this technology were not visible, impossible to anticipate and cascaded in an interactively complex manner. Perrow's Normal Accident Theory (NAT) hypothesizes that any system containing elements that are tightly coupled and interactively complex would have accidents in the normal course of operations precisely because of this combination of lack of control and inability to comprehend what was happening.

Through the examination of the Space Shuttle Columbia accident, Marais, et al., (2004) concludes that to better understand and prevent accidents requires recognition of the system as whole (physical, organizational and social) not individual components. Specific recommendations include: (1) identify safety constraints; (2) design a system to satisfy the concerns; (3) detect system changes; (4) determine how changes could increase risk over time due to internal and external pressures and (5) develop metrics and audit performance to detect changes in level of risk. 


\section{Organizational Perspectives}

Research by Weick and Sutcliffe (1999) includes five processes that help HROs manage unexpected events by thinking differently.

The cognitive processes listed in Table 2 produce a perspective referred to as mindfulness. This acuity enables a heightened awareness of discriminatory detail and increased ability to discover errors that could escalate into a crisis. These processes reduce blind spots that allow failures to accumulate and produce catastrophic outcomes.

Table2. Cognitive Processes of Mindfulness

\begin{tabular}{|l|l|}
\hline $\begin{array}{l}\text { Preoccupation with } \\
\text { failure }\end{array}$ & $\begin{array}{l}\text { Close calls, near misses } \\
\text { as failure versus success }\end{array}$ \\
\hline $\begin{array}{l}\text { Reluctance } \\
\text { to simplify }\end{array}$ & $\begin{array}{l}\text { Small errors equal early } \\
\text { warnings }\end{array}$ \\
\hline $\begin{array}{l}\text { Sensitivity } \\
\text { to operations }\end{array}$ & $\begin{array}{l}\text { Current system } \\
\text { performance }\end{array}$ \\
\hline Resilience & $\begin{array}{l}\text { Create new uses for } \\
\text { existing resources }\end{array}$ \\
\hline Deference to experience & $\begin{array}{l}\text { Operational decisions } \\
\text { migrate to expertise }\end{array}$ \\
\hline
\end{tabular}

Organizational trust and communication are key indicators of the success of HROs. Research by Worley, et al, (1999) examines the relationship between perceptions of trust and communication in the context of technology changes at three levels: organizational, workgroup and individual. The results indicate as open communication increases:

- Organizational trust and positive supervisory leadership increase;

- Workgroup cohesion and satisfaction with social rewards increase;

- Influence over work activities and satisfaction with internal rewards increase;

- Openness to and acceptance of change and active participation in change process increases
Therefore, increases in organizational trust and communication had a positive impact on the organization as it transitioned to new technology.

\section{Medical Perspective}

The Institute of Medicine reports medical errors kill approximately 100,000 people each year in American hospitals. The research problem for the medical community is the lack of a clear framework to measure the safety of health care organizations [5].

The research by Pronovost, et al, (2006) focuses on a comprehensive approach to help health care organizations reliably deliver effective interventions. The results are: (1) a scorecard framework for patient safety and effectiveness that contains domains, defined outcomes and sample performance measures and (2) a model to improve reliability that serves to engage, educate, execute and evaluate management and staff in the change process. This research emphasizes the importance of measures in the delivery of reliable patient care.

\section{Policy Perspective}

In order to determine the role of policy changes in shaping error-intolerance within the FAA's air traffic control services, O'Neil (2008) conducts a longitudinal, qualitative case study of five legislative periods (1926-2001) that result in changes in FAA. He concludes that policy changes influenced organizational changes between 1926 and 1966 and organizational changes are driven less by policy changes after 1966. This research also summarizes the eight attributes used to compare the three HROs in this paper.

\section{HRO Attributes}

The literature suggests eight common attributes that organizations possess or strive for in order to achieve low levels of error and high reliability The organizational properties ("what") (e.g., structures and funding) and the organizational structure ("how") (e.g., training, systems improvement programs) for highly reliable enterprises are described in Table 3. 
Table 3. Description of HRO Attributes

\begin{tabular}{|l|l|}
\hline Organizational Properties ("What") \\
\hline Regulatory structure & $\begin{array}{l}\text { Redundant command \& } \\
\text { control, hierarchical }\end{array}$ \\
\hline $\begin{array}{l}\text { Specialized } \\
\text { personnel requirements }\end{array}$ & $\begin{array}{l}\text { High levels of technical } \\
\text { proficiency }\end{array}$ \\
\hline Safety prioritization & Safety first \\
\hline Funding & $\begin{array}{l}\text { Target funding for error } \\
\text { reduction and reliability }\end{array}$ \\
\hline Organizational Structure ("How") \\
\hline Training & $\begin{array}{l}\text { Mandated, standardized } \\
\text { continuous }\end{array}$ \\
\hline $\begin{array}{l}\text { Technical } \\
\text { competence standards }\end{array}$ & $\begin{array}{l}\text { Repetitive training, } \\
\text { recertification systems }\end{array}$ \\
\hline $\begin{array}{l}\text { System } \\
\text { improvement program }\end{array}$ & $\begin{array}{l}\text { Identify potential error } \\
\text { and } \\
\text { mitigations }\end{array}$ \\
\hline $\begin{array}{l}\text { Communication decision } \\
\text { structure }\end{array}$ & $\begin{array}{l}\text { Centralized } \\
\text { decentralized }\end{array}$ \\
\hline
\end{tabular}

\section{Comparative Summary}

The primary mission of air traffic control does not vary (i.e. keep flights separated). A nuclear power plant's primary function also does not vary (i.e. manage the heating of a critical mass of uranium). However, medicine continues to change rapidly with increasing discoveries of how the human body works, responses to medication, and the development of new drugs and procedures. This is the fundamental property that shapes the design of the HRO.

\section{Regulatory Structure}

In all three cases, the risky operations are performed by a team with a hierarchical structure of supervision that provides redundancy. For example in the ATO, a Traffic Flow manager ensures that a given airspace is not saturated with inbound flights. In the event an airspace sector becomes too crowded, the supervisor can shift airspace boundaries or add personnel to relieve the workload. A similar procedure is also used in nuclear power plants by the plant manager, Senior Reactor Operator (SROs) and watch engineers to ensure that interactive systems supporting both reactors are operating properly. In hospitals, surgery does not exhibit this hierarchical redundancy, but patient care does with a system of attending nurses, medical technicians, residents and a hierarchy of supervisors and managers

\section{Specialized Personnel Requirements}

All three domains require the employment of skilled personnel that are certified by a regulatory (federal or state) authority with required specific training and certification. Each organization recruits from specialized training programs in which individuals must meet specific initial requirements before entering a formal training program. The requirements for a new air traffic controller, reactor operator and registered nurse are included in Table 4 $[6-9,4]$.

Table 4. Personnel Requirements by Domain

\begin{tabular}{|c|c|c|c|}
\hline & Air Traffic & $\begin{array}{l}\text { Nuclear } \\
\text { Power }\end{array}$ & Medical \\
\hline Experience & $\begin{array}{l}\text { 3Years } \\
\text { and/or } 4 \\
\text { Year } \\
\text { Degree } \\
\text { Military } \\
\text { Controller }\end{array}$ & $\begin{array}{l}\text { 3-4 Years of } \\
\text { RNPPE } \\
\text { Military } \\
\text { Reactor } \\
\text { Operator }\end{array}$ & 1 Year \\
\hline Education & $\begin{array}{l}\text { Air Traffic } \\
\text { Collegiate } \\
\text { Training } \\
\text { Initiative } \\
\text { AT-CTI } \\
\text { Degree }\end{array}$ & $\begin{array}{l}\text { Nuclear } \\
\text { Engineering } \\
\text { Degree }\end{array}$ & $\begin{array}{l}\text { Nursing } \\
\text { Degree }\end{array}$ \\
\hline Testing & $\begin{array}{l}\text { Air Traffic } \\
\text { Selection } \\
\& \\
\text { Training } \\
\text { AT-SAT } \\
70 \%\end{array}$ & $\begin{array}{l}\text { Generic } \\
\text { Fundamental } \\
\text { Exam (GFE) } \\
80 \%\end{array}$ & $\begin{array}{l}\text { National } \\
\text { Council } \\
\text { Licensure } \\
\text { Exam } \\
\text { (NCLEX- } \\
\text { RN) }\end{array}$ \\
\hline $\begin{array}{l}\text { Initial } \\
\text { Training }\end{array}$ & $\begin{array}{l}\text { Air Traffic } \\
\text { Basics } \\
\sim 700 \mathrm{hrs} . \\
\end{array}$ & $\begin{array}{l}\text { Site Specific } \\
\text { Plant } \\
\text { Processes }\end{array}$ & $\begin{array}{l}\text { Nursing } \\
\text { Degree }\end{array}$ \\
\hline
\end{tabular}

\section{Safety}

Safety is a priority for all three domains as evidenced by mission statements, training programs and safety measures documented, tracked and reported on scorecards. Each organization also has a specific office that focuses on safety compliance and quality assurance activities. Safety first and do no harm are an integral part of the culture. 


\section{Funding}

The three HROs are financed differently. The Air Traffic Organization is federally funded. It receives funding from the Airport and Airway Trust Fund which is revenue derived from aviation-related excise taxes on passengers, cargo and fuel and the General Fund. In FY 2011, the ATO operations budget was approximately \$7billion [10]. The Pacific Gas and Electric Company's operating revenues (includes utility rates) was approximately $\$ 14$ million in 2011[11]. And, the Medical Center's total operating revenue (includes patient fees and insurance rates) for July 1, 2011 to June 6, 2012 was about \$1.8million [4].

\section{Training}

For the En Route option, instruction at an Air Route Traffic Control Center (ARTCC) includes completion of Assistant Controller Training, Nonradar and Radar Associate Controller Training, and Radar Controller Training and qualifying on all positions and sectors within that area. Each phase of the courses involves academic study, both classroom and computer-assisted laboratory simulations, and on-the-job instruction. Jacksonville Center, for example, has six areas, 42 operational sectors and between six and nine sectors per area. The traffic mix is about $50 \%$ air carrier, $30 \%$ general aviation and $20 \%$ military [2]

The training target for En Route is three years for controllers to reach certified professional controller (CPC). The actual number of years was 2.62 for fiscal years 2009 and 2010 and 2.79 for fiscal year 2011 [12].

The NRC's initial reactor operator licensing process consists of the following: (1) a written GFE (covering reactor theory, thermodynamics, and components); (2) a site specific written examination covering plant systems, emergency and abnormal plant evolutions, and plant-wide generic knowledge and abilities and (3) a site-specific operating test consisting of a crew-based, dynamic simulator performance demonstration, an individual, task based walk-through operating test concerning control room and in-plant systems, and required plant administrative tasks.

To become a licensed SRO takes about 10-12 years (including engineering degree, almost four years of responsible nuclear power plant experience and two year licensing time)[13].

Initial training and specialized personnel requirements are similar for nurses. It takes approximately five years to become a registered nurse [4].

\section{Technical Competence Standards}

To maintain individual standards of technical competence each organization requires highly specialized repetitive training and/or recertification.

Air traffic controllers take refresher training to maintain proficiency through team and facility briefings, required reading and computer and laboratory lessons. The training is tailored to meet the needs of an individual facility and includes, but is not limited to, mandatory briefings, supplemental and skills enhancement activities.

Refresher training includes topics such as lost aircraft orientation, tower visibility procedures, prevention of runway incursions weather conditions, and minimum safe altitude warning procedures. There is also supplemental training on new and revised procedures, regulations and equipment.

The SRO license expires after six years. The renewal program must be approved by the NRC and include: (1) written evidence of his or her experience under existing license; (2) certification from facility licensee that the applicant is a safe and competent performer; (3) completion of requalification program for the facility.

The requalification process can take up to 24 months and includes completing a comprehensive requalification written exam and an annual operating test; lectures (e.g. plant instrumentation and control systems, radiation control and safety); and on-the-job training on approximately 31 plant activities by walk through or simulator (e.g. reactor startups, loss of electrical power) [14].

Nurses and physicians must complete a recertification or license renewal process that differs by specialty and by state. For the medical center, the requirements are outlined in the state Revised Code Title XLVII Occupations-Professions-Sections 4723.24, License Renewal and 4731.281, Continuing Education. 
Physicians with a certificate to practice medicine and surgery must renew it biennially and complete 100 hours of continuing medical education (CME) approved by the state medical association.

Registered nurses must renew their licenses biennially as well. The state board requires each nurse to complete 24 contact hours of continuing nursing education (CNE) including one hour of the training on the state nursing laws and statues. Contact hours are described as training hours received through direct instruction.

The Cincinnati Children's Medical Center is officially recognized by the Accreditation Council for Continuing Medical Education (ACCME) to provide continuing medical education for physicians and the American Nurses Credentialing Center's Commission on Accreditation for nurses.

There are some states, however, that do not require CNE related activities for renewal. For example, the renewal period for Virginia is two years with no CNE requirements; the renewal requirement for Maryland is 1,000 practice-related hours or Board of Nursing approved refresher course within the past five years; and the District of Columbia requires 24 contact hours of practiced-related $\mathrm{CNE}$ within the past two years. Eighteen of the 50 states have no specific contact hour requirement for renewing a license every two years; on the other hand, Connecticut is on an annual renewal period [15].

\section{Formal System Improvement Programs}

For these enterprises, promoting and maintaining a safety culture includes providing structured programs for employees to report safety concerns.

Employees delivering air traffic services in Terminal, En Route and Oceanic and Systems Operations use the Voluntary Safety Reporting Programs (VSRPs) to identify and correct potential safety hazards. The Air Traffic Safety Action Program (ATSAP) is confidential and provides a mechanism to report concerns such as noncompliance with FAA directives potential safety events or perceived problems with policies, procedures, equipment, automation, and publications used to provide air traffic control services at a local, regional or nation level.
An Event Review Committee (ERC) consisting of representative from FAA and labor (National Air Traffic Control Association (NATCA), the ATO, and the Office of Aviation Safety Oversight (AOV) assesses and analyzes each report to identify actual or potential safety problems and to ensure appropriate action. An air traffic safety event is described as the result of an actual or potential loss of required separation, or other situation that degrades air traffic safety within the NAS occurring during the provision of air traffic control services. The safety issues are resolved through corrective action versus punishment or discipline [16].

There are several internal process improvement programs used by PG\&E (including nuclear power) to manage risk throughout the enterprise. The programs are designed to identify signs of potential error, formulate corrective actions and subsequently increase system performance and reliability. Two initiatives are described below.

Enterprise Risk Management (ERM) identifies processes and procedures that could have a potentially catastrophic impact on public safety. Cross-functional teams of managers and subject matter experts detect risks, evaluate the probability and severity of consequences, and develop mitigation actions. The top risks are prioritized and assessed every two to three years, as well as mid-cycle if a new risk emerges.

Close Call Reporting incorporates safety principles of FAA's Aviation Safety Action Program where the objective is to foster an environment where reporting human and organizational performance events are encouraged to prevent recurrence. The report includes what happened, how it happened and what should be done to prevent recurrence. Management and union: (1) treat a human error as a learning opportunity; (2) agree not to take positive discipline actions (e.g., written letter in personnel file) when human errors are reported, given that injury, equipment damage, customer impact or a violation of PG\&E's values has not occurred; and (3) report anonymously through special hotlines or a self-report to the employee's supervisor [17].

The Center for Simulation and Research is dedicated to reducing and preventing medical errors through multidisciplinary education and training. Serious Safety Event (SSE) reduction training incorporates technical (algorithms of care) and non- 
technical skills (teamwork and communication) required for potentially life-threatening emergencies in high-risk clinical simulations. Simulations are specific to a particular clinical environment (Emergency Department, ECMO, Critical Care, Radiology, and Operating Room). The use of multidisciplinary teams of caregivers is encouraged for all courses [4].

\section{Communication/Decision Making Structure}

Air traffic control operates in a centralized policy making environment and a decentralized operational structure. For example, authority migrates to an individual controller to increase separation distances between aircraft or deny access to certain routes and altitudes to defuse potentially dangerous situation.

At power plants, localized responsibility that requires action can be dangerous so the operation follows a centralized decision making structure. Actions taken in a very narrow context can negatively impact other parts of the system due to the tight coupling of systems. For example, a test requiring a brief shutdown of an instrument air pressure system on a reactor during a scheduled maintenance overhaul can be postponed if there is concern the instrument might be interconnected to its counterpart in a second operating reactor. The engineering drawings are not accepted as definitive proof. A supervisory engineer has to complete a walk-through of the entire system to ensure total independence from the second reactor before the testing can proceed [18].

In health care, judgments are made at the frontline and decision-making processes vary depending on the level of urgency. During critical conditions, authority shifts to the member with the most expertise without regard to rank.

\section{Safety Measures}

Each HRO has system level performance measures that use an enterprise-wide scorecard to align employee's performance to the higher level strategic goals. However, this paper addresses only some of the safety related metrics.

Air traffic control focuses on: (1) runway incursions, (2) system risk event rates, (3) separation violations, and (4) number of collisions. Runway Incursions (RIs) are reported and tracked at airports with operational air traffic control towers. A runway incursion is any occurrence at an aerodrome involving the incorrect presence of an aircraft, vehicle or person on the protected area of a surface designated for the landing and takeoff of aircraft. The FAA tracks four categories of RIs: Categories A, B, $\mathrm{C}$, and $\mathrm{D}$ but only includes those with the highest risk of collision, Category A and B incursions, in the measure. The metric unit is the rate of category $A$ and $\mathrm{B}$ RIs per million operations. The rate of Category A and $\mathrm{B}$ incursions continues to decrease Fiscal Years 2008 through 2011 as shown in Table 5[19].

Table 5. Runway Incursions

\begin{tabular}{|l|l|l|l|l|l|}
\hline $\begin{array}{l}\text { Fiscal } \\
\text { Year }\end{array}$ & FY'08 & FY'09 & FY'10 & FY'11 & FY'12 \\
\hline Target & 0.509 & 0.472 & 0.450 & 0.450 & 0.395 \\
\hline Actual & 0.427 & 0.227 & 0.117 & 0.138 & TBD \\
\hline
\end{tabular}

The children's hospital measures system level patient and employee safety through: (1) adverse drug events, (2) catheter-associated bloodstream infections and surgical site infections, (3) serious safety events (e.g. variation from expected practice followed by death, severe permanent harm, moderate permanent harm or significant temporary harm), and (4) OSHA recordable injuries.

Length and quality of life is measured through disease-specific health outcomes including remission rates and physical functioning. One key measure of quality of life for patients with cystic fibrosis is lung function (also known as $\mathrm{FEV}_{1}$ ). The capacity to breathe and access oxygen normally, as measured by $\mathrm{FEV}_{1}$, ranges in healthy people from $85 \%$ to $115 \%$ percent. Children with cystic fibrosis on average lose about $2 \%$ to $4 \%$ of their lung function each year. The Center has seen consistent improvement in lung function performance in six to 12 year old patients from $85 \%$ in 2000 to approximately $100 \%$ in 2010 [4].

The Diablo Canyon Nuclear Power Plant pays attention to: (1) nuclear reactor accidents, (2) acute radiation exposures resulting in fatalities, (3) release of radioactive materials that result in significant radiation exposures, and (4) release of radioactive 
materials that cause significant adverse environmental impacts. In FY 2012, there were no significant accident sequence precursors of a nuclear reactor accident and no events with radiation exposures to the public and occupational workers that exceeded abnormal occurrence criterion [20].

\section{Results}

This paper identifies more similarities than differences in the properties of three HROs (air traffic control, nuclear power and medical.)

The similarities include: (1) risky operations are performed by a team with a hierarchical structure of supervision that serves to add redundancy; (2) use of a scorecard framework to track and report progress of safety performance measures; (3) regulatory oversight of operations at the federal and/or state level; (4) employment requires specialized, skilled personnel that are certified by a regulatory (federal or state) authority and training that is continuous and specialized; and (5) formal system safety improvement programs. Air traffic specialists can voluntarily report safety concerns without punishment or discipline through the Air Traffic Safety Action Program (ATSAP). Nuclear power uses a similar system called the Close Call Reporting Program (CCRP) for employees to report safety problems without penalty. And to reduce and prevent errors, hospitals conduct Serious Safety Event (SSE) reduction training with multi-disciplined teams along with automated reporting tools.

There are three differences among the HROs. First, financial structure, location and scale do not impact organizational performance. Air traffic control operations are coordinated across the US through a distributed operational structure while nuclear power plants and hospitals have a centralized operational structure in a campus environment. Second, STEM (science, technology, engineering and math) degrees are required for medical and nuclear power but not for air traffic control specialists. And third safety in air traffic control resides in being able to disaggregate the larger system in potentially dangerous circumstances, in medical emergencies, expertise shifts to the person with the most knowledge regardless of rank and nuclear power emphasizes a more holistic approach with the integration of both analytic and action capabilities applied during emergency operations.
Air traffic control, nuclear power and medical have trained personnel that are dedicated to performing high-risk operations safely for extended periods of time. These enterprises continue to accomplish their missions with redundant systems and structures designed improve reliability and avoid potentially catastrophic errors.

\section{References}

[1] September 2010, ADMINISTRATOR'S FACT BOOK, Washington, D.C., Federal Aviation Administration

http://www.faa.gov/about/office_org/headquartersoffices/

[2] Federal Aviation Administration (FAA), Air Traffic Organization (ATO), http://www.faa.gov/about/office_org/headquarter s_offices/ato

[3] Pacific Gas \& Electric (PG\&E) Home Page

http://www.pge.com

[4]Cincinnati Children's Medical Center http://www.cincinnatichildrens.org/about/corporate/f acts-figures/

[5]Institute of Medicine (IOM) November 1999. To Err is Human: Building a Safer Health System, Washington, D.C. National Academies Press. http://www.iom.edu

[6] How to Become an Air Traffic Controller http://www.faa.gov/about/office_org/headquarters_of fices/ahr/jobs_careers/occupations/atc/path1/

[7] FAA. 2012c. "Order JO 3120.4M, Air Traffic Technical Training - National Policy."

http://www.faa.gov/air_traffic/publications/.

[8]NRC.2000. "Qualification and Training of Personnel for Nuclear Power Plants

http://pbadupws.nrc.gov/docs/ML0037/ML00370693 2.pdf

[9] International Atomic Energy Agency (IAEA).2002. Recruitment, Qualification and Personnel for Nuclear Power Plant's Safety Guide

http://www-

pub.iaea.org/MTCD/publications/PDF/Pub1140_scr. pdf 
[10]Federal Aviation Administration (FAA), 2013, FY2013President's Budget Submission

http://www.faa.gov/about/budget/

[11] PG\&E.2011.PG\&E Corporation Pacific Gas and Electric Company 2011 Annual Report.

http://www.pgecorp.com/investors/financial_reports/ annual_report_proxy_statement/arpdf/2011/2011_An nual_Report.pdf.

[12] Federal Aviation Administration (FAA). 2012, A Plan for the Future: 10 Year Strategy for the Air Traffic Control Workforce 2012-2021

http://www.faa.gov/air_traffic/publications/controller _staffing/media/cwp_2012.pdf

[13] NRC.2007.Operator Licensing Examination Standards for Power Reactors NUREG-1021, Rev. 9, Supp. 1.

http://pbadupws.nrc.gov/docs/ML0729/ML07297031 5.pdf

[14]Nuclear Regulatory Commission (NRC).1994.NRC:10CFR55.59 Requalification

http://www.nrc.gov/reading-rm/doc-

collections/cfr/part055/part055-0059.html

[15]Law, Emily, 2006, State-by-State Guide for RN License Renewal Requirements

http://www.nursingcenter.com

[16] FAA. 2012b. "Order JO 7200.20, Voluntary Safety Reporting Programs (VSRPs)."

http://www.faa.gov/air_traffic/publications/

[17] Pacific Gas \& Electric Company.2012. PG\&E's Sustainability Journey: Recommitting and Refocusing for the Journey Ahead http://www.pgecorp.com/corp_responsibility/rep orts/2010/index.html/.

[18] Klein, Rochelle, et.al. 1995. "Organizational Culture in High Reliability Organizations: An Extension."

http://hum.sagepub.com/content/48/7/771.refs/ht $\mathrm{ml}$

[19]FAA FY 12 Portfolio of Goals, FY2012 Methodology Report, FAA Destination 2025 Performance Metrics

http://www.faa.gov/about/plans_reports/media/FY12 _POG.pdf

[20] NRC's Summary of Performance and Financial information for fiscal Year 2012

http://www.nrc.gov/reading-rm/doc-

collections/nuregs/staff/sr1542/v18/

\section{Acknowledgements}

The author would like to thank the individuals who supported the completion of this paper: Lance Sherry, PhD, Director of the Center for Air Transportation Systems Research (CATSR), George Donohue, PhD, John Shortle, PhD, Akshay Belle, Houda Kerkoub Kourdali, CATSR/GMU, Juan Mantilla of GMU, Lonnie Bellamy and Brandye Scott of Bellamy Management Services.

\section{Email Addresses}

Plewis11@gmu.edu

2013 Integrated Communications Navigation and Surveillance (ICNS) Conference

April 23-25, 2013 